\title{
Representing the Indus Body: Sex, Gender, Sexuality, and the Anthropomorphic Terracotta Figurines from Harappa
}

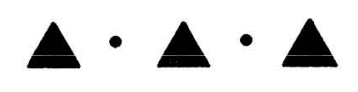

\author{
SHARRI R. CLARK
}

IN THIS PAPER, THE CORPUS OF ANTHROPOMORPHIC TERRACOTTA FIGURINES FROM HARAPPA, a major urban center of the Indus civilization, is used to explore Indus conceptions of sex, gender, and sexuality as they are expressed in representations of the body. The Indus (or Harappan) civilization, the earliest urban civilization of South Asia (c. 2600-1900 B.c.), at its peak extended over much of what is now Pakistan and northwestern India. Representing something of a cultural "veneer" (Meadow and Kenoyer 1997:139), it was characterized by large cities with extensive water and sanitation systems, a writing system that still awaits decipherment, an emphasis on small, elegant art and sophisticated craft technology, and a conspicuous absence of monumental art (Kenoyer 1998; Possehl 1998). In this "faceless civilization" (Possehl 1998:279), three-dimensional anthropomorphic representations include a few stone and bronze statues, along with other small objects, and a large corpus of terracotta figurines. The terracotta figurines from Harappa and other Indus civilization sites are one of the most abundant and elaborate classes of representational artifacts of this vast civilization, particularly in the western regions. Without deciphered texts, the figurines are one of the richest sources of information regarding Indus concepts of sex, gender, sexuality, and other aspects of Indus social identity.

While acknowledging the inherent difficulties in "dis-integrating" these concepts and other forms of social difference, sexual difference, understood in terms of more fluid, graded, or "nuanced" (see Meskell 1999:73-76) but distinct notions of sex and gender, can be used to frame a meaningful inquiry into ancient social systems. Using sex and gender in a more flexible and informed way also means acknowledging that sexual difference may not have been a primary or an independent concern of ancient societies (Joyce 2000:182-183). While rigid Cartesian frameworks derived from modern Western notions may not be completely applicable to ancient societies (e.g., Meskell 1999, 2001), the ability to consider sex and gender separately in archaeological interpretation is still an important

Sharri R. Clark is a Ph.D. candidate in the Department of Anthropology, Harvard University, Cambridge, Massachusetts.

Asim Persertives, Vol. +2, No. 2 (1) 20013 by University of Hawai'i Press. 
option, and the fact that societies react differently to biological differences between men and women argues for some separation of sex and gender (see Sørensen $2000: 55 \mathrm{ff})$.

Such an approach to the complex interrelationship of sex, gender, and sexuality requires explicit definitions of these terms. In this paper, sex (or sexual identity) is defined as the biological differentiation of male and female (or rarely neither or both), based upon observable physiology (e.g., primary and secondary sex characteristics), hormones (gonadal sex), and genetic structure (chromosomal sex), and is, to some degree, culturally constructed. Gender (or gender identity) is defined here as psychological differentiation, or sense of self, beyond the body, based upon dynamic and negotiated sociocultural constructs of maleness, femaleness, or some combination of these concepts. Sexuality (or sexual identity) is also largely socially constructed and conventionally seen as an overlapping category with gender and sex, but focuses on sexual preference or desire, a key issue that has been neglected or tied to reproduction in most gender studies (Herdt 1994). In addition, sexual difference is used here to refer to the integration of all three interrelated concepts as an aspect of social identity.

This paper is not intended as a new treatise on feminist theory in South Asian archaeology, using the Indus civilization as a "case study," nor does it claim to present a definitive or comprehensive exposition of Indus conceptions of the body and sexual difference. It is, rather, a critical examination of representations of the body in the Indus civilization, particularly the anthropomorphic terracotta figurines from Harappa, uninformed by texts (not yet deciphered) but informed by recent advances in feminist theory that view sexual difference in the context of broader social difference and identity.

\section{Sex, Gender, Sexuality, and Archaeological Research}

While it is now generally accepted that genetic or chromosomal sex depends upon the presence of the Y chromosome, specifically upon genes such as SRY (e.g., Goodfellow 2000), and that chromosomal variations may result in at least five phenotypical sexes (Fausto-Sterling 1993), it is no longer tenable to suggest that differences in personality and character based on gender are innate (Alcoff 1997 :335). Clearly, "[s]ex:gender is no longer a clear-cut paradigm" (Knapp and Meskell 1997:187), yet many archaeological studies continue to focus on the binary categories sex (as biology) and gender (as culture), if they are considered at all. Sexuality is a third, and sometimes implicit and overlapping, category in this complex triangle of embedded social constructs (e.g., Meskell 1999:70), only recently specifically addressed in archaeology (e.g., Schmidt and Voss 2000), that may be expressed in a society's representations of the body.

The ongoing debates within the feminist movement and in "gender archaeology" (see Conkey and Gero 1997; Meskell 1999, 2001; Sørensen 2000; and others for summaries and different perspectives), briefly outlined here, attest to the complexity of research on these closely interwoven concepts. Early calls for visibility and equity for women in archaeology (e.g., Bertelsen et al. 1987 [1979 workshop]; Kenyon 1969) culminated in a critical article (Conkey and Spector 1984) that served as the catalyst for gender archaeology as an ongoing critique and subdiscipline. However, initial emphases on biology (which ignores sexuality) and 
on women and the simplistic dichotomies "(biological) sex (male:female): (social) gender (masculine:feminine)" were soon challenged on the basis that sex is also mediated through culture (Butler 1990; Laqueur 1990; Moore 1988). Responses to the limitations of the "sex: gender" paradigm have included calls for additional sexes and genders (e.g., Herdt 1994) or a spectrum of sexes (e.g., Nordbladh and Yates 1990) or no distinction between sex and gender (e.g., Schmidt 2000).

More flexible conceptions of sex and gender have resulted, acknowledging the multiple variations in sex and gender and in the relationships between these two dimensions over a lifetime, concomitant with the recognition that studies of social groups should include multiple factors. These factors include, in addition to gender, human agency, class, and other social affiliations (e.g., Brumfiel 1992). Butler $(1990,1993)$ has suggested that gender can be viewed as a social performance or a "way of being" in a society. A concern with the body has also emerged, reflected in the focus on the social and lived (spatio-temporally contextualized) body (Gatens 1996; Grosz 1994, 1995). Because of the complex and variable relationship between sex and gender (and sexuality), the ongoing debate centers on whether any distinction between sex and gender can be maintained. While "second wave" feminists generally argue that it can, some "third wave" feminists consider the "sex:gender" opposition an artificial Western Cartesian construction and favor, alternatively, a more holistic approach to understanding identity that interpolates "sexual difference" (rather than distinguishing between sex and gender) with other "axes of difference" (see Moore 1988:10), such as life cycle, status, and ethnicity. All of these developments have resulted in more broadly integrated studies in archaeology (e.g., Gilchrist 1999; Joyce 2000).

Conceptions of sex, gender, and sexuality are not cross-culturally uniform (e.g., Brettel and Sargent 1993; Herdt 1994; Nanda 2000). Since they often contradict the modern Western paradigm, they may provide broader analogies for archaeological interpretation. Although much modern Western writing has romanticized and idealized non-Western cultures' apparent positive valuation of diversity, most societies' attitudes toward gender diversity are ambivalent or even hostile (Nanda 2000:4) and not necessarily balanced between the sexes (Brettel and Sargent 1993). Gender variant traditions are known from the earliest civilizations of the ancient Near East, which were contemporary with the Indus civilization, to the present (see Roscoe 1996:212 fn 71, 217-218). For example, in Mesopotamia (Sumer/Akkad) gala/kurgarrî/assinnu, effeminate cross-dressing (possibly castrated) priests of Inanna in Sumer (or Ishtar in Akkad), sang lamentations to the gods to procure their goodwill and appear to have engaged in ritual and other homosexual practices (Roscoe 1996:213-217).

The hijras provide a particularly pertinent ethnographic and historic example of gender variance for this study ${ }^{1}$ as an ancient tradition that has coexisted with Hinduism and later Islam in South Asia since it first appeared in Vedic texts (c. 1500 в.с.) after the end of the Indus civilization, although direct lineage from the Indus civilization is unlikely. A hijra (an Urdu term) is a nonreproductive individual who is physiologically neither male nor female (usually intersexed or originally male with male genitalia removed), but socially feminine and either sexually celibate or sexually active with men. Hijras see themselves as "neither man nor woman" in a somewhat burlesque feminine gender role that often involves musical performance and encompasses what Westerners would consider eunuchs, 
homosexuals, transsexuals, hermaphrodites, and transvestites (Nanda 1999, 2000). Hijras in India are usually devotees of the Mother Goddess (a pre-Hindu tribal deity incorporated into Hinduism), often undergoing emasculation as a form of ascetic devotion, and have the power to bless with fertility or to curse with infertility (Nanda 1999, 2000; Roscoe 1996).

Despite recent theoretical advances and ethnographic, historical, and archaeological evidence of complex conceptions of sex, gender, and sexuality that do not conform to Western conceptions, much of archaeological research has been slow to utilize more flexible concepts of sex and gender. Over thirty years ago, in his pioneering comparative study of prehistoric Near Eastern figurines, Ucko (1968) called for a consideration of more than two sexes and two genders. Yet, in most discussions of the figurines and other evidence from the Indus civilization, there has been little attention to sexual difference and other social difference until recently.

\section{Previous Research on Sex and Gender in the Indus Civilization}

A recent study of the post-processual approach in South Asian archaeology has suggested that the concern with gender in archaeology has had very little effect on South Asian archaeology (Boivin and Fuller 2002:205-207). Perhaps it should not be surprising that early work did not explicitly address the topics of sex and gender (or sexuality) beyond making vague references to physical attributes, as it may have been considered either unnecessary (as sex was "obvious") or inappropriate at the time. However, interpretations of Indus iconography and religion have often rested upon the sexual identity of certain figures (e.g., Sullivan 1964).

Based upon the early excavations at Mohenjo-daro and Harappa, Marshall (1931) produced the first comprehensive analysis of the Indus civilization, which strongly influenced almost all interpretations of Indus society and its conceptions of sex and gender that followed. First, he interpreted some of the female figurines as representations of the tribal and pre-Hindu Mother Goddess who embodies female energy, thus relating Indus religion to Shaktism and "sexual dualism" (Marshall 1931:57-63). Second, he suggested that the linga (phallus) and yoni (vulva) might have been worshipped in the Indus civilization (Marshall 1931:5863; but see Dales' [1984] refutation). Finally, Marshall and others (e.g., Mackay 1938; Vats 1940; Wheeler 1947) used implicit criteria such as the absence of male genitalia, "small" or "rudimentary" breasts, hairstyles, headdresses, skirts, and Hindu analogy to determine the sex of Indus figures.

Using these criteria, twice as many female figurines as male figurines were identified in the initial excavations at Harappa (Vats 1940:292). However, since less complete figurine fragments were discarded and since male figurines do not have genitalia depicted as often as female figurines have breasts depicted, this quantification potentially underrepresents the male figurines. These sample and representational biases, along with subjective criteria such as hairstyle, resulted in over-classifying figurines as female representations and in over-emphasizing the female figurines at Mohenjo-daro (see Ardeleanu-Jansen's [1993] critique of Marshall [1931]) and at other sites (e.g., Jarrige 1984:129). While studies of terracotta figurines from Neolithic and Bronze Age sites in South Asia have not specifically investigated sex and gender beyond classifying the figurines as male, 
female, or neither (for example, Ardeleanu-Jansen 1993, 2002; Dales 1960), many of these studies have provided valuable insights regarding gender roles and changes over time (e.g., Jarrige 1991) and have facilitated the study of sex and gender (particularly the analysis of sex and other attributes employed by Dales [see Dales et al. 1991]).

Only a few studies have focused specifically on gender in the Indus civilization (Atre 1998; Wright 1991; see also chapter 10 in Possehl 2002). In probably the most comprehensive attempt to address sex, gender, and sexuality in the Indus civilization to date, Kenoyer (1998) has addressed a number of important topics. Although he relies heavily on ethnographic analogy, the general discussion is thoughtful and intriguing. For the first time aspects of Indus society such as "childbirth and childhood," "womanhood," and "manhood" are specifically addressed.

\section{EXPLORING SEX, GENDER, AND SEXUALITY THROUGH THE ANTHROPOMORPHIC FIGURINES FROM HARAPPA}

The interpretation of figurines in archaeological research is notoriously problematic (e.g., Lesure 2002), partly because of the predilection for assumptions and the biases of our own cultural filters. These include assumptions that figurines without physiological sex characteristics are female, equating sex and gender, viewing sex and gender as binary and static oppositions, and even the assumption that gender was important to depict and static in ancient societies. Since the script of the Indus civilization has not yet been convincingly deciphered (see Possehl 1996), the texts created by the Indus people themselves cannot be used to understand sex, gender, and sexuality in Indus society. Therefore, other sources such as anthropomorphic representations and human remains must be consulted for information about these concepts in Indus society. The terracotta figurines are important, not because they explicitly represent these concepts, but because they implicitly embody conceptions of sex, gender, and sexuality in Indus society.

This paper uses the corpus of anthropomorphic terracotta figurines from Harappa to investigate how sex is depicted in representations of the Indus body and to explore the corpus for possible representations of gender as it relates to other aspects of social difference and identity. While a small subset of the terracotta figurines from the excavations at Harappa have been published (e.g., Dales et al. 1991; Meadow et al. 2001; Vats 1940; Wheeler 1947), this paper relies on the author's recording of the attributes of the figurines for her dissertation and on contextual information from excavation field notes. While the larger corpus of figurines from Harappa has been analyzed, an assemblage of terracotta figurines from Trench 39 on Mound AB at Harappa is particularly important, because it provides a full corpus of recovered figurine fragments from a complete stratigraphic sequence with buildings, hearths, drains, pits, and wash deposits. This sequence dates from the earliest period (the Ravi phase or Period 1, c. 3300-2800 B.C. ${ }^{2}$ ) to one of the latest periods (the Late Harappan phase or Period 5, c. 1700-1300 B.C.). It is important to remember that the absence of figurines of particular types in this assemblage may be the fortuitous result of the kinds of deposits found in this area of the site. 
Although their contexts do not directly inform us of their primary (and other) functions, the fact that the figurines in each period are usually found broken in trash deposits throughout the site (as at many ancient Near Eastern sites) is significant. These figurines were apparently discarded at the end of their "social lives" (see Appadurai 1986), along with other terracotta objects such as animal figurines, carts, beds, and tops, as well as seals, tablets, pottery, and bones. As noted earlier by Dales (1991b:65), no figurines have been found in mortuary contexts at Harappa, as the "post-cremation urns" described by Vats (1940:292), which sometimes contained figurine fragments, were actually sump pots (Meadow, pers. comm. 2002). Careful attention has been paid to the fragmentary nature of the figurine corpus, and all percentages are based upon figurine fragments with relevant body parts represented. For example, only figurine fragments with a lower torso are considered in the percentages for male genitalia.

\section{Representing the Indus Body}

How does one consider sexual and other difference in a civilization in which the views of the people cannot be accessed through texts? Surviving gender variant traditions in South Asia, such as the hijras, may provide some insight into ancient South Asian societies. However, in any ancient civilization sex, gender, and sexuality may have been viewed completely differently. Sex and gender may not have always been important to depict, and conceptions of sex, gender, and sexuality may not have been fixed or consistent within a society. Furthermore, sexual difference is only one factor that may influence the representation of the body, and figurines may represent naturalistic or ideological concepts such as bodies sanctioned by authority or stereotyped bodies.

Moreover, modern perceptions of the Indus body have changed. Although early descriptions of a few female figurines included "exaggerated hips" (Marshall 1931:246, fn 1) or broad hips, as well as "prominent" breasts (Mackay $1938: 277)$, it was also noted that in most figurines the waist is not unduly small nor are the breasts, the hips, and the pubic area (or the "generative organs") exaggerated (Gordon and Gordon 1940; Mackay 1938:269; Wheeler 1968:91). Despite a later increased emphasis on the sexualized and symbolic body linked with fertility (Dales 1991a:140), the exaggerated breasts, hips, and thighs and the protruding abdomens usually associated with fertility are not typical of the majority of Indus female figurines. While this misperception persists, a number of scholars now agree that the figurines do not exaggerate the female body or necessarily represent fertility (e.g., Ardeleanu-Jansen 1993).

The lack of clothing on the figurines has also been interpreted as evidence for a fertility function (Dales 1991a:140; Dales et al. 1991:227; Kenoyer 1998:137) or a cultic function (Ardeleanu-Jansen 2002:211), rather than as a reflection of Indus dress (Kenoyer 1998:137; Mackay 1938:265; Marshall 1931:33). However, nudity does not necessarily signify eroticism or fertility. It may signify age (youth) or lower status in ancient art (Meskell 1999), and one might expect the nude male figurines to be ithyphallic if they represented virility. In addition, most female figurines are not nude. Neither are the male figurines always nude (for example, Vats 1940:294:12, P1. 77; also see Kenoyer 1998:137), as is commonly 
suggested (e.g., Atre 1998:164). In any case, the figurines may not have been displayed nude (or semi-nude); they may have been adorned with perishables such as cloth. The depiction of belts on the female figurines may indicate codes of modesty in female dress in the Indus civilization (Marshall 1931:339). While covering the female body may indicate that there were some social constraints regarding Indus women's bodies, the belt, sometimes decorated with what may represent a girdle of beads, may have had additional symbolic value. For example, ancient Egyptian women sometimes wore amulets or girdles across the pelvis and stomach to prevent evil from entering the body through the navel or vagina (Meskell 1999:49). It should be remembered that Western concepts associated with clothing the body, such as "virginity" and "chastity," had no importance in other ancient Near Eastern civilizations, such as Mesopotamia (Westenholz 1998:64), and may have no relevance here.

Studies comparing official media such as monuments and seals with popular media, such as figurines and pottery in contemporary Mesopotamia (Pollock 1991) and in later Mesoamerica (Brumfiel 1996; Joyce 1996, 2000), have also shown that the female subject, unlike the male subject, is depicted in inconsistent and even contradictory ways in different representational media. While the Indus terracotta figurines have been interpreted as a popular (domestic) medium by some archaeologists (e.g., Mackay 1938:259; Marshall 1931:50), the paucity of other representations even at major Indus sites leaves only the seals, tablets, and a few pieces of statuary as potentially "official" media for comparison. Only one iconographic scene on the seals and tablets recovered from Harappa (repeated on multiple tablets) includes what appears to be a female figure with breasts, nude and unadorned (unlike the female figurines), holding two felines by the throats (see Kenoyer 1998; Meadow and Kenoyer 2000; Meadow et al. 1997). Unfortunately, no stone statues of females have been found for comparison. However, a naturalistically styled bronze figurine found at Mohenjo-daro (Marshall 1931:4445,345 , Pl. 94:6-8) is depicted nude with small breasts, narrow hips, and long legs (unlike the terracotta figurines), which may imply youth or ethnicity (as Marshall suggested) or may simply reflect the differences in messages, audiences, and styles of different media in the Indus civilization.

\section{Identification: Primary and Secondary Sex Attributes and Other Attributes}

The female figurines have been overemphasized in most studies of the Indus civilization, which has sometimes resulted in the interpretation of even ambiguous and very fragmentary figurines as female. This overidentification misrepresents both the identifiability of the figurine fragments, which are almost always broken, and the relative ratio of female figurines to other figurines. Primary sex characteristics such as genitalia and breasts are the most reliable indicators of sex if it is represented, while secondary sex characteristics, such as beards, are less reliable indicators. Fragments without these indicators must remain questionably identified or unidentified, although some may be identified with some probability using other attributes. The subjective nature of this process is especially clear when identifying ambiguous figurines without sex characteristics or with both male and 
female attributes, as we often look for our own culturally constructed demarcators of identity with regard to sex, gender, and sexuality.

At Harappa, the physiological attributes that distinguish female figurines are conical breasts (without distinct nipples), although not all figurines that may represent females have breasts (see Table 1 and Fig. 1). At least 94 percent of the female figurines from Harappa have breasts. Genitalia are rarely depicted in representations of females in Indus art, with the bronze "dancing girl" from Mohenjo-daro (Marshall 1931:44-45, 345, Pl. 94:6-8) providing a rare exception. Most Indus female figurines wear a belt or a short skirt that covers the pubic area.

Marshall's (1931:338-339) general description of the figurines from Mohenjodaro as "[i]n almost every case" female with a girdle around the loins, loaded with jewelry, and wearing a fan-like headdress with panniers has been taken by many (for example, Atre 2002) as a description of the "typical" Indus female figurine. While the fan-shaped headdress is the most common headdress on female figurines at Harappa (approximately 70 percent of those with identifiable headdresses), fewer than 30 percent of these figurines have panniers and fewer than 13 percent have more than one necklace. It is thus inaccurate to consider this the "typical" Indus female figurine. It is more accurate to speak of a "typical" Indus female figurine body type with pointed conical breasts of medium size in relation to overall body size, fairly wide hips, and a flat abdomen (see Fig. 2). Breasts and hips are usually proportional to the waist, giving the impression of a youthful, curvaceous figure with no features overemphasized. In fact, the breasts of the figurines from Harappa are so conical that when found detached, they may be mistaken for the "cones" that sometimes decorate the heads (see Fig. 2b) or belts (see Fig. 2a) of some figurines.

Some of the earliest figurines from the Ravi and Kot Diji phases (c. 3500-2600 B.C.) at Harappa are seated with a schematic upper body and wide hips with joined legs (see Fig. 1a) similar to contemporary examples from Mehrgarh (e.g., Jarrige 1991) and Rehman Dheri (Flavin et al. 1995). These figurines do not usually have breasts or genitalia nor do they wear belts, which makes their identification as female figurines tenuous. However, the rotund buttocks of these early figurines are more characteristic of female physiology (pelvic skeletal structure and musculature) than male physiology (K.A.R. Kennedy, pers. comm. 2000). Some of the early figurines from sites such as Rehman Dheri (Flavin et al. 1995) and a few from the Ravi and Kot Diji phases at Harappa have small flattened round applied breasts (see Fig. 1b). However, figurines with conical breasts completely dominate the figurine corpus from the beginning of the Harappa phase (c. 2600 B.c.) onward (see Fig. 1c-f, h). Since there is no clear transition between the flat round breasts of the early figurines at Harappa and the larger conical breasts that typify Indus female figurines, the latter type may have supplanted the former type at Harappa.

At Harappa, male figurines are distinguished by primary sex characteristics such as genitalia and/or small flattened round applied "nipples" (see Fig. 3c-e) or by secondary sex characteristics such as beards. The depiction of genitalia provides the least ambiguous identification of male figurines. Representations of genitalia usually include two applied testicles (or sometimes a single applied scrotum) and 
Table i. Identifiability with Sex Characteristics and Other Attributes Related to Sex and Gender

\begin{tabular}{|c|c|c|c|c|}
\hline \multirow[b]{2}{*}{ CERTAINTY OF IDENTIFICATION } & \multicolumn{2}{|c|}{ TRENCH 39 ASSEMBLAGE } & \multicolumn{2}{|c|}{ ENTIRE ASSEMBLAGE } \\
\hline & PROBABLE & CERTAIN & PROBABLE & CERTAIN \\
\hline \multirow{4}{*}{$\begin{array}{l}\text { Total Female Anthropomorphic } \\
\text { Figurine Fragments } \\
\text { Females with breasts }\end{array}$} & $43.6 \%$ & $16.2 \%$ & $45.2 \%$ & $24.1 \%$ \\
\hline & $(202 / 463)$ & $(75 / 463)$ & $(1143 / 2527)$ & $(609 / 2527)$ \\
\hline & $93.8 \%$ & $100.0 \%$ & $94.1 \%$ & $100.0 \%$ \\
\hline & $(75 / 80)$ & $(75 / 75)$ & $(595 / 632)$ & $(609 / 609)$ \\
\hline \multirow[t]{2}{*}{ Females with belts } & $89.7 \%$ & $84.0 \%$ & $90.1 \%$ & $85.9 \%$ \\
\hline & $(105 / 117)$ & $(21 / 25)$ & $(528 / 586)$ & $(225 / 262)$ \\
\hline \multirow[t]{2}{*}{ Females with "female" headdresses } & $66.7 \%$ & $57.1 \%$ & $73.3 \%$ & $71.7 \%$ \\
\hline & $(42 / 63)$ & $(20 / 35)$ & $(423 / 577)$ & $(289 / 403)$ \\
\hline \multirow{4}{*}{$\begin{array}{l}\text { Total Male Anthropomorphic } \\
\text { Figurine Fragments } \\
\text { Males with genitalia }\end{array}$} & $5.6 \%$ & $1.7 \%$ & $16.1 \%$ & $8.9 \%$ \\
\hline & $(26 / 463)$ & $(8 / 463)$ & $(407 / 2527)$ & $(224 / 2527)$ \\
\hline & $38.5 \%$ & $71.4 \%$ & $47.3 \%$ & $80.8 \%$ \\
\hline & $(5 / 13)$ & $(5 / 7)$ & $(123 / 260)$ & $(121 / 151)$ \\
\hline \multirow[t]{2}{*}{ Males with nipples } & $50.0 \%$ & $50.0 \%$ & $50.3 \%$ & $50.0 \%$ \\
\hline & $(7 / 14)$ & $(7 / 14)$ & $(164 / 326)$ & $(163 / 326)$ \\
\hline \multirow[t]{2}{*}{ Males with beards } & $8.3 \%$ & $50.0 \%$ & $16.2 \%$ & $28.8 \%$ \\
\hline & $(1 / 12)$ & $(1 / 2)$ & $(48 / 297)$ & $(46 / 160)$ \\
\hline \multirow[t]{2}{*}{ Males with genitalia only } & $0 \%$ & $0 \%$ & $8.9 \%$ & $8.9 \%$ \\
\hline & $(0 / 13)$ & $(0 / 7)$ & $(15 / 260)$ & $(15 / 151)$ \\
\hline \multirow[t]{2}{*}{ Males with nipples only } & $0 \%$ & $0 \%$ & $6.5 \%$ & $11.7 \%$ \\
\hline & $(0 / 14)$ & $(0 / 14)$ & $(11 / 326)$ & $(11 / 326)$ \\
\hline \multirow[t]{2}{*}{ Males with beards only } & $0 \%$ & $0 \%$ & $3.0 \%$ & $3.0 \%$ \\
\hline & $(0 / 2)$ & $(0 / 2)$ & $(5 / 168)$ & $(5 / 168)$ \\
\hline \multirow[t]{2}{*}{ Males with genitalia and nipples } & $44.4 \%$ & $66.7 \%$ & $35.0 \%$ & $60.0 \%$ \\
\hline & $(4 / 9)$ & $(4 / 6)$ & $(78 / 222)$ & $(78 / 130)$ \\
\hline \multirow[t]{2}{*}{ Males with genitalia and beards } & $0 \%$ & $0 \%$ & $6.5 \%$ & $11.7 \%$ \\
\hline & $(0 / 4)$ & $(0 / 1)$ & $(11 / 168)$ & $(11 / 94)$ \\
\hline \multirow[t]{2}{*}{ Males with nipples and beards } & $11.0 \%$ & $50.0 \%$ & $12.1 \%$ & $21.2 \%$ \\
\hline & $(1 / 9)$ & $(1 / 2)$ & $(32 / 264)$ & $(32 / 151)$ \\
\hline \multirow[t]{2}{*}{ Males with genitalia/nipples/beards } & $0 \%$ & $0 \%$ & $6.0 \%$ & $10.6 \%$ \\
\hline & $(0 / 4)$ & $(0 / 1)$ & $(10 / 168)$ & $(10 / 94)$ \\
\hline \multirow[t]{2}{*}{ Males with "male" headdresses } & $0 \%$ & $0 \%$ & $7.4 \%$ & $10.0 \%$ \\
\hline & $(0 / 12)$ & $(0 / 2)$ & $(22 / 297)$ & $(16 / 160)$ \\
\hline \multirow{2}{*}{$\begin{array}{l}\text { Total Ambiguous Anthropomorphic } \\
\text { Figurine Fragments }\end{array}$} & $0 \%$ & $0 \%$ & $<0.1 \%$ & $<0.1 \%$ \\
\hline & $(0 / 463)$ & $(0 / 463)$ & $(9 / 2527)$ & $(9 / 2527)$ \\
\hline \multirow{2}{*}{$\begin{array}{l}\text { Total Unidentified Anthropomorphic } \\
\text { Figurine Fragments }\end{array}$} & $50.8 \%$ & $82.1 \%$ & $38.7 \%$ & $67.0 \%$ \\
\hline & $(235 / 463)$ & $(380 / 463)$ & $(977 / 2527)$ & $(1694 / 2527)$ \\
\hline \multirow{2}{*}{$\begin{array}{l}\text { Total Anthropomorphic Figurine } \\
\text { Fragments }\end{array}$} & $100 \%$ & $100 \%$ & $100 \%$ & $100 \%$ \\
\hline & $(463)$ & $(463)$ & $(2527)$ & $(2527)$ \\
\hline
\end{tabular}

Note: These numbers represent subsets of the anthropomorphic figurine fragments, and all percentages are based upon plausibility of representation (for example, only figurine fragments with an upper torso are considered in percentages for nipples or breasts, while only figurine fragments with a head and both an upper and a lower torso are considered in percentages for the combinations of genitalia, nipples, and beards). "Certain" females have breasts, while "probable" females may have only belts or headdresses typically found on females. "Certain" males have genitalia, nipples, and/or beards, while "probable" males may have only seated posture or headdresses typically found on males. In each case, the "certain" group is a subset of the "probable" group. Figurines with both male and female characteristics are included in the appropriate male and female percentages, as well as in "Total Ambiguous Figurine Fragments." 


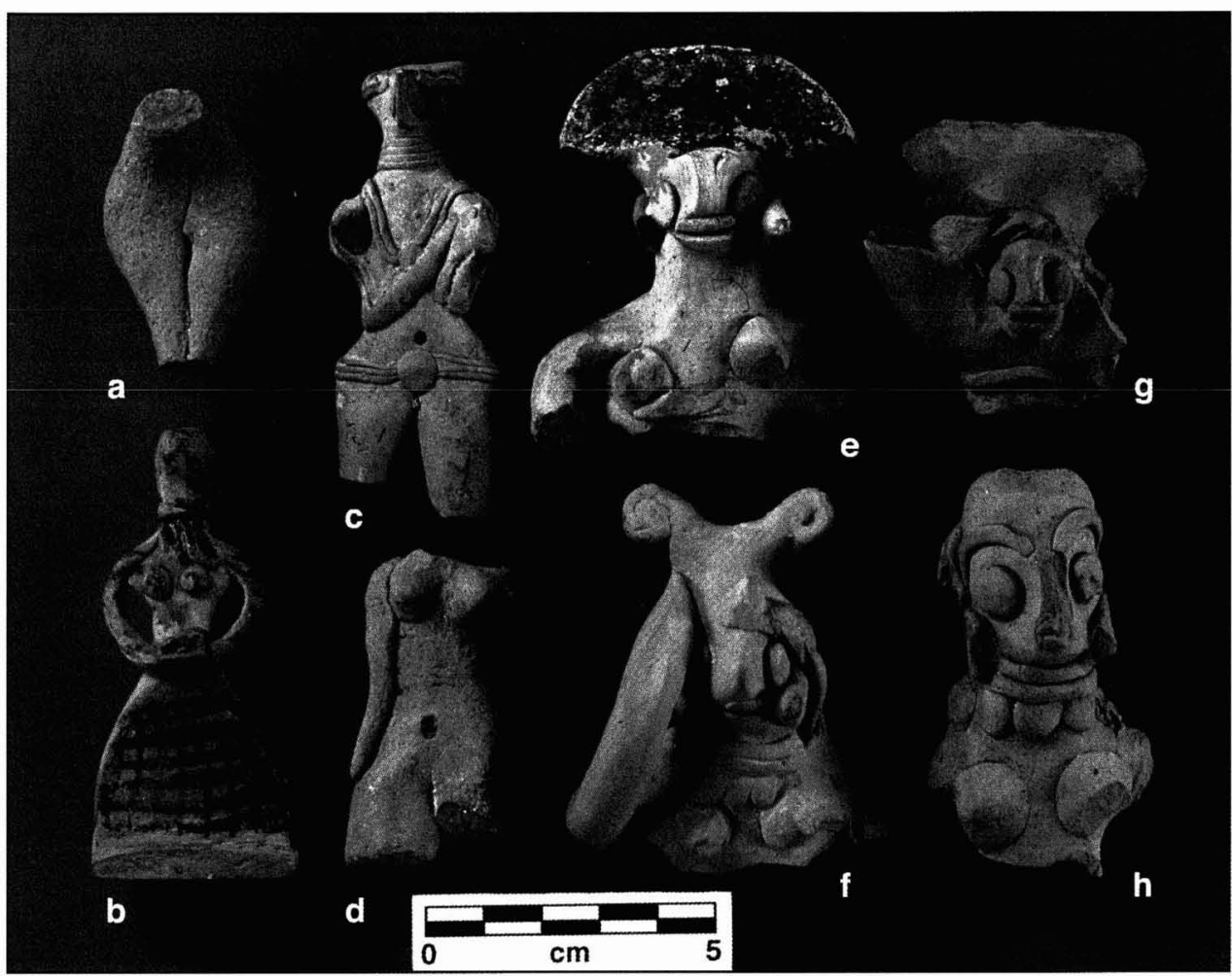

Fig. 1. Some examples of female figurines from Harappa (top to bottom, left to right): a: H98-4220; b: H98-3456; c: H99-4222; d: H2000/2222-1; e: H98-3708; f: H88-882; g: H99-4981; and h: $\mathrm{H} 2000-4997$ (photograph by the author).

an applied, usually superimposed, penis. Sometimes (especially with the seated figurines), only the penis, the testicles, or the scrotum is depicted. No male figurines recovered thus far from Harappa are depicted as ithyphallic, despite this implication in previous publications (Dales 1991a; Dales et al. 1991:227).

Since at Harappa nipples usually occur with male attributes such as genitalia and beards when they occur, they also seem to be male attributes. The nipples on Indus male figurines are relatively large, unlike the nipples on male figurines in other ancient civilizations (e.g., Jarrige 1991:93, Pl. 78; Marcus 1996:290, Fig. 6). While the applied nipples found on male figurines at Harappa appear to be very similar to the applied breasts on the early female figurines (which differ from the conical breasts of later female figurines), male nipples are usually smaller than female breasts in proportion to the upper torsos of the figurines (compare Fig. 1b with Fig. $3 d-e)$ or are distinguishable through other attributes, and male figurines have not yet been found in the earliest levels at Harappa. The figurines with nipples, now recognized as depictions of males, were sometimes identified in early excavation reports as female figurines (e.g., Mackay 1938:282, Pl. LXXVI:22) or as male figurines with "small" or "rudimentary" breasts (e.g., Marshall 1931:341). Only recently have explicitly identified "nipples" been noted as a common 


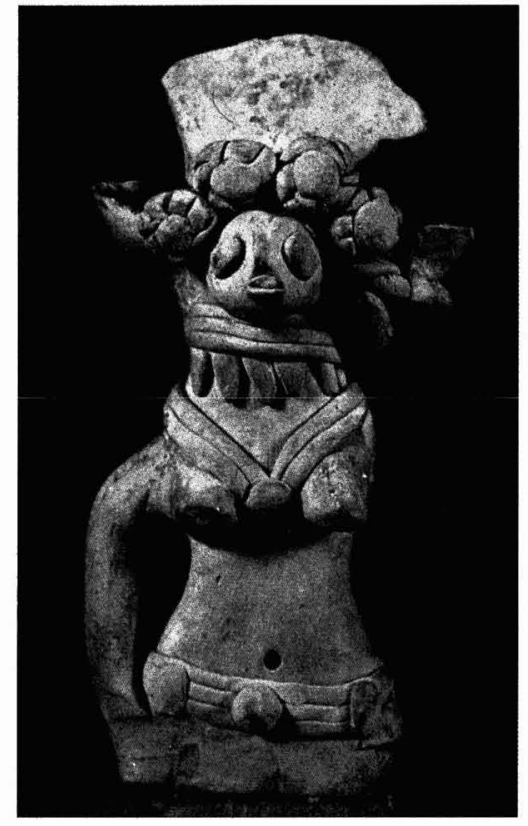

a

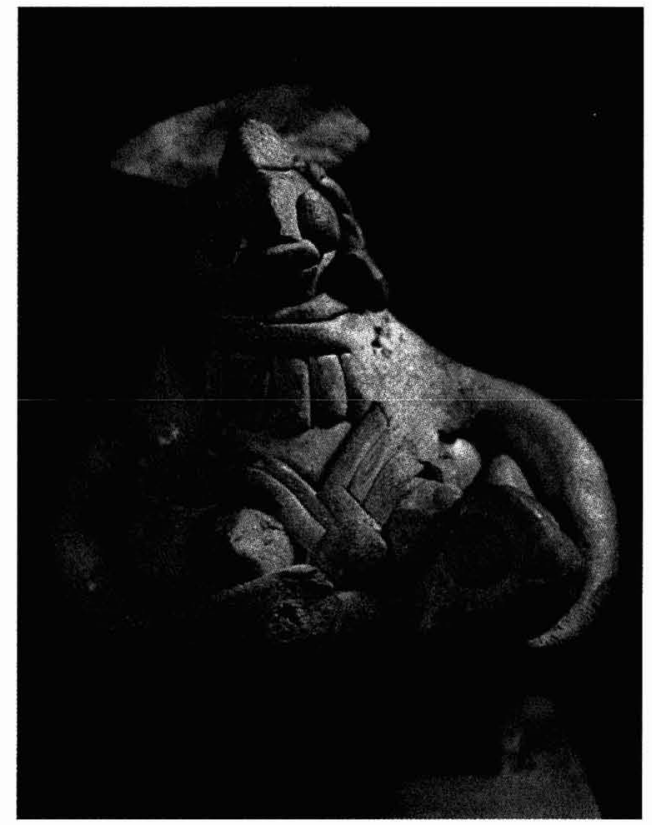

b

Fig. 2. Some examples of more complete Indus female figurines: a: Indus female figurine with "typical" attributes such as a fan-shaped headdress (usually without panniers), earpieces, necklaces, belt or skirt (unusually elaborate in this case), and a curvaceous flat body with conical breasts (height: $13.2 \mathrm{~cm}$; photograph courtesy of J. M. Kenoyer); b: "globular" female figurine with an infant (height: $7.5 \mathrm{~cm}$; photograph courtesy of the National Museum of India).

feature on male figurines (Ardeleanu-Jansen 2002:211; Clark 2001; Kenoyer 1998:137).

As shown in Table 1, the most frequently depicted "male" attributes are: (1) genitalia; (2) nipples; and (3) beards. These percentages are even higher if the seated figurines with bent knees, which rarely have sex attributes, are excluded. Male figurines seldom have only one male attribute or the combination of all three male attributes. In other words, all figurines with any of these male attributes are most likely to have a combination of nipples and one other male attribute.

Since the upper torso is sometimes missing from the figurine fragments due to breakage, the certain identification of female figurines is relatively low at Harappa (see Table 1). Although applied conical breasts are sometimes detached, it is usually possible to distinguish between the scars left by detached breasts and nipples because of the size discrepancy between the breasts and the nipples relative to the size of the upper body of the figurine. Approximately 16 percent of the assemblage from Trench 39 and less than 25 percent of the larger assemblage can be identified with certainty as female. In some cases, other attributes usually associated with female figurines at Harappa, such as particular headdresses (for example, fan-shaped headdresses), earpieces, and belts, may be useful in identification (see Table 1). Considering these additional attributes raises the percentage of identifiable female figurines to approximately 45 percent in both assemblages. 


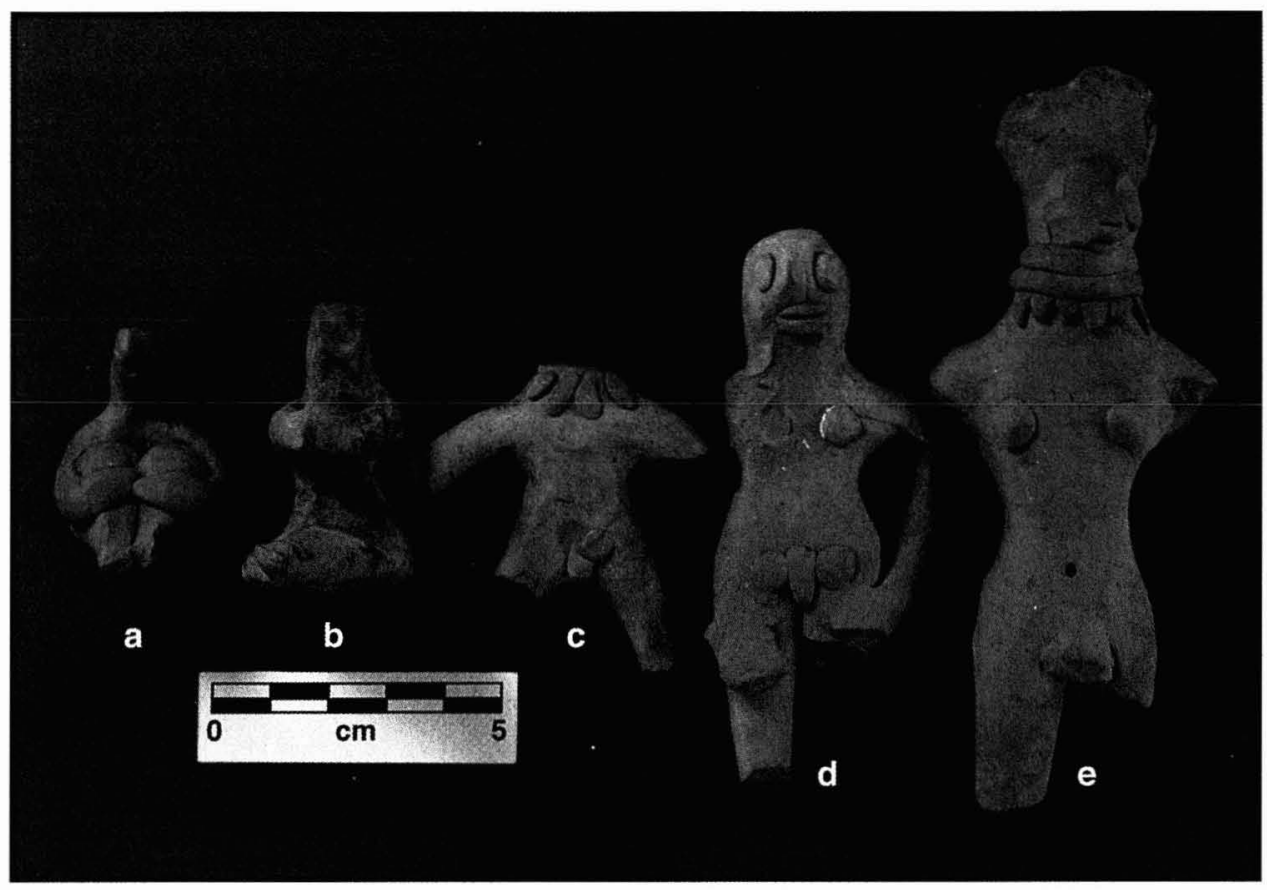

Fig. 3. Some examples of male figurines from Harappa (left to right): a: H96-3063; b: H94-2301; c: H99-4973; d: H98-3495; and e: H87-388 (photograph by the author).

Even fewer figurine fragments, only approximately 2 percent of those from Trench 39 and fewer than 9 percent of the larger assemblage, can be identified with certainty as male (see Table 1). Other attributes such as posture can also be useful in the identification of male figurines at Harappa. For example, seated figurines with arms encircling the knees (Fig. 3a) always have male attributes when sex attributes are depicted. Male figurines rarely have headdresses, earpieces, or belts (see Table 1), and the headdresses found on male figurines are usually different from those found on female figurines, although some hairstyles are found on both. Necklaces are found on both, although more female figurines than male figurines have at least one necklace, and female figurines are more likely to have multiple necklaces. Considering these additional attributes raises the percentage of identifiable male figurines to fewer than 6 percent of the figurines from Trench 39 and approximately 16 percent of the larger assemblage.

Thus, even with all attributes considered, a maximum of approximately 45 percent of the figurine fragments can be identified as probably representing females and approximately 16 percent can be identified as probably representing males. The high percentage of figurine fragments from Trench 39 that are not identifiable with certainty as male or female ( 82.1 percent) or as probably male or female (50.8 percent) reflects the high degree of fragmentation in this assemblage. Perhaps more significant is the fact that in the identifiable portion of the Trench 39 assemblage, the ratio of female to male representation is more than $9: 1$ with certainty and almost $8: 1$ probably. The bias toward female representation in the 
Trench 39 ratio is much higher than in the identifiable portion of the larger selected assemblage, which is less than $3: 1$ with certainty or probability. Clearly, assemblages from particular areas may differ significantly from the larger corpus.

While some figurines from Harappa have no explicit female or male attributes, a few figurines have both female and male attributes. At least one figurine from Harappa is depicted with a beard, breasts, and a fan-shaped headdress. Another figurine with nipples and male genitalia also wears a (broken) form of fan-shaped headdress typically found on female figurines (Fig. 3e). Other figurines with (male) nipples wear (typically female) belts. Identification of these figurines is extremely subjective, but (male or female) sex has been identified here on the basis of primary (and secondary) sex characteristics, regardless of other gendered attributes such as headdress. The figurine with both breasts and a beard is identified as both male and female. (These figurines are included in both the male and female figurine fragment totals and in "Total Ambiguous Figurine Fragments" in Table 1.) Although rare, similar examples may be found at other Indus sites such as Mohenjo-daro (see Marshall 1931:346, Pl. XCIV:11).

Since the assemblage from Trench 39 was completely recovered and analyzed, it may provide a more realistic measure of identifiability than the larger selected assemblage. However, the Trench 39 assemblage may not be truly representative since it comes from particular types of deposits from only one area of the site. Furthermore, some caution should be exercised in using the frequencies of identifiable male and female figurine fragments as a measure of male vs. female representation, since breakage has influenced this statistic. Male figurines are more likely to be identified with certainty on the basis of more attributes in different areas of the body than are female figurines. For example, a bearded head, two halves of an upper torso with nipples, and a lower body with genitalia from the same figurine might appear to represent four male figurines.

The presence of sex attributes on most of the Indus figurines suggests that sex (and/or gender) was usually important to depict. In some cases, the extra step of adding these separately applied sex attributes may have been inadvertently omitted. It is also possible that attributes such as the seated posture with knees drawn up toward the chest impeded the depiction of primary sex attributes or rendered them unnecessary. Since breasts are so often depicted on female figurines, the absence of breasts and other attributes related to sex on some figurines may imply that they are representations of males or intentionally androgynous or "sexually neutral" figures (e.g., Kenoyer 1998). In most cases, the absence of sex and other attributes seems to have been a conscious and meaningful choice that was meant to convey a particular message.

\section{Gender and Life Cycle: Age, Life Stage, and Reproductive Status}

Sexual maturity and reproductive viability often influence the conception of gender (Gailey 1987; Nanda 2000). For example, in many societies children are not regarded as socially male or female until they reach the age of puberty. In ancient Aztec society, for instance, gender was considered a potential, and infants (although given gender-specific ornaments) were considered "raw materials" until the process of education with regard to gender role and occupation expressed 
in body modification (for example, piercing), hairstyle, dress, and tools had produced from them social (gendered) persons with a "social skin" (Joyce 2000).

Life cycle has become an exciting new focus of study in archaeology (see Gilchrist 2000; Meskell 2002), and studies have shown that age, life stage, reproductive status, and gender are sometimes combined influences on representations such as figurines (e.g., Cyphers Guillén 1993; Joyce 2000; Lesure 1997). For example, Marcus (1998) has identified specific hairstyles on figurines from Oaxaca that indicate both age and marital status in the feminine gender role.

Most of the figurines from Harappa appear to represent adult reproductive females with fully developed breasts. The only reliable (but optional) attribute indicating life stage for males, the beard, is found on fewer than 29 percent of the male figurines. Thus, it is more difficult to assess whether the male figurines represent adults. The seated and other figurines without male or female attributes (sometimes without facial features as well) may represent immature males, although beards are sometimes among the sex characteristics when any are represented, or they may be simply schematic representations of people without any consideration of sex or gender.

The reproductive aspect of the feminine gender role is sometimes, though not often, depicted in the figurines from Harappa. For example, the usually hollow "globular" often considered a depiction of pregnancy with a votive function (originally suggested by Marshall [1931:33 supra] and supported by others [e.g., Mackay 1938:269, 272; Vats 1940:29ff]). Alternatively, these figurines may represent caricatures (During Caspers 1979:352-353), dwarves (Marshall 1931:344), or opulence, as obesity may symbolize wealth and prosperity (Mackay 1938:279) or maturity (Kenoyer 1998:134). An interpretation other than pregnancy or fertility is supported by the discovery of a "globular" male figurine with a beard and nipples at Harappa. Very few "globular" figurines (fewer than 3 percent of the total corpus) have been recovered at Harappa.

Depictions of infants (usually nursing) with female figurines (Figs. 1c, 2b) emphasize both the biological and the social roles of Indus women in reproduction. While observations such as, "[m]any female votive figurines carry a suckling infant" (Kenoyer 1998:132) give the impression that child-rearing is a frequently depicted feminine role, very few of the female figurines (fewer than 4 percent of the total corpus) from Harappa are depicted with infants or children (see Figs. 1c, 2b). Despite a tentative suggestion otherwise (Vats 1940:295), none of the male figurines from Harappa are depicted with infants, although some are depicted with infants in the pre-Harappan period elsewhere (Jarrige 1991:91-92).

At Harappa the most obvious prepubescent representations, infants still attached to the torso (and breast) of an adult (Figs. 1c, 2b), are usually very schematic without sex attributes (which would be hidden against the adult's torso anyway) and often without eyes. Depictions of children beyond infancy are more difficult to identify. According to Western conceptions, one might expect depictions of children to be smaller and possibly nude, with less prominent sex characteristics (if any) than adults. The statement that, "[m]ost figurines of infants and children are male" (Kenoyer 1998:132) is apparently based upon the absence of breasts on these figurines, although children of both sexes may have been represented 
without sex attributes or possibly with sex attributes (and sexually) in ancient art (Meskell 1999:101). For example, in Classic Maya art children are generally represented as "small-scale adults" with only a few details such as hairstyle (indicating life stage) and relative size differentiating them from adults (Joyce 2000:122132). While a few smaller figurines from Harappa with fan-shaped headdresses and what appear to be nipples may represent immature females, it is unclear whether other smaller figurines with mature breasts and adult dress represent immature or adult females.

\section{Gender and Other Social Difference}

Gender roles are often associated with particular occupations. Although most figurines from Harappa are represented simply standing or sitting, others are depicted in possibly gendered activities. For example, some figurines indicate that Indus men may have kept birds (see Vats 1940:295, Pl. LXXVI:14) and practiced animal husbandry, work associated with women in some other ancient societies (Joyce 2000:299). A few other seated figurines with extended arms holding an oblong object on the central ridge of the platform formed by the seated lower body (e.g., Vats 1940:296, Pl. LXXVI:23) represent women presumably preparing food or grinding grain (e.g., Kenoyer 1998:134). Two of these figurines that have nipples or smaller breasts may represent males engaged in a typically female occupation or female adolescents. While perfectly plausible, the assumption that these figurines represent household activities may be restrictive. Perhaps these figurines represent women in other activities such as grinding minerals for faience production or kneading clay for pottery production, which could place Indus women in larger spheres of production and provide a different perception of women's roles in Indus society. Although the representation of domestic or other production may argue against supernatural representation or ritual function (Dales et al. 1991:227; Marshall 1931:49; Wheeler 1968:92), these figurines may also symbolize an association between women and ritual (for fertility or prosperity) through production. In any case, the figurines may lend support to Kenoyer's (1998:133) suggestion that, "some women of the cities may have had important social and ritual positions," which may be corroborated by possible matrilocal burials ${ }^{4}$ in the Harappan period cemetery at Harappa.

Gender is also influenced by status. For example, the names of women of lower occupation and status (such as slaves and prostitutes) in some ancient Greek texts are grammatically neuter (e.g., the name "Phrynion" in Pseudo-Demosthenes' Against Neaera). Lower status may be indicated by nudity in ancient art (e.g., Meskell 1999). Conversely, the relationship between gender and status may be examined under the assumption that higher status is reflected in more elaborate representations. At Harappa, female figurines are generally dressed and ornamented more elaborately than males. A few male figurines are also elaborately detailed and ornamented, and many of these have beards and nipples. Since many male figurines at Harappa have few details (lacking even facial features), the more elaborate male figurines may represent males whose higher status or individual personhood was more important to express. Of course, dress and ornamentation may also indicate ethnicity (e.g., Kenoyer 1998:117, 134). 


\section{Gender Ambiguity}

Gender ambiguity in figurines and in other representations is found in many ancient societies (e.g., Joyce 2000). At Harappa, the small subset of figurines with mixed attributes is composed solely of males (or male/female) in feminine dress, which correlates with patterns found in the ethnographic record (Nanda 2000) and in mythology (O'Flaherty 1980:284). When the mixed attributes include belts, it is impossible to determine whether the presence of nipples implies the presence of male genitalia beneath the usually feminine attribute or whether a physiologically male and female body is represented. Covering the pubic area in these cases may have been an obfuscation of male sex/gender attributes (hiding male genitalia or emasculation beneath a feminine "overlay" as the hijras do) or some other expression of gender variance.

One possible explanation for these mixed attributes is the natural phenomenon of hermaphroditism, the phenotypical presence of both male and female reproductive organs in the same individual. However, since physiological androgyny is quite rare and since it was often socially undesirable with extreme sanctions in some ancient societies, it is unlikely that it was the source of any androgynous symbolism or myth (O'Flaherty 1980:290-291). Moreover, figurines do not necessarily mirror nature or a society's views on human physiological androgyny. For example, in ancient Greece where hermaphroditic children were sometimes killed (see Diodorus Siculus 32.12.3; O'Flaherty 1980:291), bisexual divinities (including Hermaphroditos) were included in Greek mythology and images (for example, terracotta figurines) with both male and female sexual features were widely used as votive offerings (see Ajootian 1997).

The mixture of sex attributes on figurines may also represent a number of sexual and gender identities expressed through cross-dressing or androgyny. Some degree of cross-dressing is not unusual in most societies, and it may be related to age. For example, in the Ferozepur District of the Punjab, a son born after the death of previous sons might be dressed as a girl and even have his nose pierced like a girl for the first ten years of childhood in hopes that his life would be spared (Kang 1988:156). Kenoyer (1998:136-137) has also noted the, "occasional overlap of gender ornamentation" (necklaces and bangles) along with braids and skirts on both male and female figures on Indus seals, tablets, and figurines and has suggested that, "[o]verlapping or androgynous styles may reflect a fluidity of styles or cross-dressing."

Some terracotta figurines from Harappa with no sex attributes or mixed sex/ gender attributes may offer glimpses of Indus cosmology and ritual. The unusual seated figurines with raised hands pressed together (Fig. 3b) are usually assumed to be male (or eunuchs) due to the absence of breasts and male genitalia, although none of those recovered thus far has nipples or beards either. Other examples with no sex attributes include composite anthropomorphic/animal figurines that may represent magical or even shamanistic transformation or mythical beings. A few of the male figurines with mixed attributes (nipples and a belt) wear a peculiar headdress with two upward projections more like animal ears than horns, usually bound with a fillet, and a beard. Like the priests and ritual figures in other ancient societies (for example, Mesopotamian gala/kurgarru/assinnu, Greco-Roman 
galli, and South Asian hijra [see Roscoe 1996]), these figurines appear to represent adult males in female dress. However, the figurines from Harappa have beards and possibly animal attributes, suggesting magical or shamanistic transformation.

In his classic study of shamanism, Eliade (1964) includes change of sex, male/ female duality, asexuality, and ritual androgynization in the characteristics typically used to represent shamans. Although the definition of shamanism is contested, shamans are still generally associated with transcendence and harnessing both male and female sexual potential, including simulated androgyny in the form of masquerade and transvestism (e.g., O'Flaherty 1980:297; Schmidt 2000). Androgyny or gender transgression may be seen as a mode and a symbol of transcendence. Nanda (2000) has suggested that sex/gender diversity is closely linked with cosmology. In fact, many creation myths include androgynous creator deities (see O'Flaherty 1980:283-285), and mixed sex and gender attributes may be represented in ceremonial costume and have cosmological significance as well (Joyce 2000). Thus, the representation of sexual duality, asexuality, and androgynization in addition to depictions of human/animal transformation and composite animals implies a cosmological significance for at least some of these figurines.

\section{CONCLUSION}

The study of sex and gender in archaeology has never been a monolithic paradigm, but rather a dynamic collection of critiques. Sex and gender are no longer regarded as a binary opposition (biological:social), but rather as closely (and by some, inextricably) interwoven concepts that represent a continuum of ideas that vary cross-culturally. Most archaeologists, including "second wave" and "third wave" feminists, would agree that sexual difference is only one form of social difference in an integrated and complex network that is constantly being negotiated. Thus, it is increasingly clear that our reconstructions of the past should acknowledge the complex interaction between axes of difference such as sex, gender, life cycle, status, and ethnicity for all members of society and should consider how aspects of social identity are projected in representations of the body. As illustrated by the well-known South Asian tale of the blind men who each tried to describe an elephant by examining only one part (see Buddhist Sutra Udana VI.4; also the poem by John Godfrey Saxe), isolated inquiries that consider only one aspect of a society may result in incomplete and inaccurate perceptions of it. Exploring gender as an integrated aspect of ancient societies (without focusing solely on women) should also result in gender archaeology becoming a less distinct subdiscipline as it becomes interwoven with all aspects of the discipline and integrated with its social theories (Sørensen 2000:5).

Just as sex can no longer be viewed as simply biological, the body can no longer be viewed as simply a natural object; both are also cultural constructs. Bodies are sexed by societies, generally as variations upon male and female (Gatens 1996), and body imagery can reflect these societal norms. Since both the norms of the social group and the experiences of the individuals in that social group are of interest and clearly interact to structure human societies, accommodating the singularity of individual experience and a multiplicity of social identities is also important to our understanding of ancient societies (Meskell 1999:2122, 50, 2001:189). However, focusing on the individual fails to approach society 
as institutions and structures or gender as ideology and as normative and regulatory processes (Sørensen 2000:13, 55-56). Moreover, the potential scope of inquiry for most archaeologists is constrained by the typically low resolution of archaeological data, with incomplete preservation of material culture at best and without textual correlates at worst. Therefore, individual experience is not always accessible through excavated material culture. Neither can gender be excavated, as it may not have explicit material effects (Sørensen 2000:53). Like any archaeological material culture then, the terracotta figurines cannot be considered a realistic representation of all aspects of Indus society or of the types and numbers of individuals in it (Bailey 1996:291; Joyce 1996:189). The data are also constrained by what the Indus people chose to represent in the figurine corpus and by other issues such as preservation.

Only about half of the figurine fragments recovered from Harappa are identifiable as female or male (Table 1). When sex attributes are absent, sex may have been implied by other attributes such as dress or posture. In addition to breasts, "female" attributes typically include particular headdresses, earpieces, and belts, while male genitalia, nipples, and beards, as well as seated posture with arms encircling the knees, can be considered "male" attributes. Headdresses and hairstyles on male and female figurines usually differ, although some are found on both. Necklaces are found on both, although more often and in greater abundance on female figurines. Most figurines do not exaggerate the female body or eroticize the male body through ithyphallic representation. In fact, the covered lower body of the female representations (Figs. 1,2) may deemphasize or imply control of sexuality and fertility, while the nudity of the male figurines and the explicit and exaggerated depiction of nipples (see Fig. 3), may indicate a heightened consciousness of male sexuality. The presence or absence of sex attributes on the figurines may also reflect the influence of other aspects of social difference such as life cycle, status, occupation, and ethnicity, as sex and gender may not have been the primary concern.

Multiple sex and gender attributes on Indus figurines are rare. At Harappa, the small subset of figurines with mixed attributes is comprised solely of males (or male/ female figurines) in feminine dress or with feminine headdress (see Fig. 3e). Covering the lower body in these cases may be a deliberate obfuscation of male genitalia (or emasculation) or the representation of a physiologically female lower body. These figurines may represent variant gender roles in Indus society, accommodating hermaphrodites, sexual variance, androgyny, and cross-dressing. These and other figurines may have also had cosmological significance. Denial of one's sexual desires and even emasculation are still marks of the religious devotee and the ascetic, and sexual duality or androgyny are often attributes of supernatural figures such as creator deities and shamans (e.g., Eliade 1964; Nanda 2000; O’Flaherty 1980).

Most figurines from Harappa do not depict any particular activity or occupation associated with either sex or gender, but a few may provide insights into Indus gender roles. For example, the biological and social reproductive roles of adult women, but not men, are sometimes depicted. Men's gender roles may have included animal husbandry, and women's gender roles may have included the domestic production of food and possibly craft production, which could place Indus women in larger spheres of production and provide a different perception of women's roles in Indus society. 
In the identifiable subset, female figurines significantly outnumber male figurines at Harappa and at other Indus sites, a bias that is not mirrored in the iconography of the seals and tablets or statuary at Harappa or at other Indus sites. These differences in representation in different media may support the suggestion that figurines are more likely folk or household representations, while seals, tablets, and statuary may represent a more official or elite iconography and ideology (e.g., Brumfiel 1996; Joyce 1996, 2000; Pollock 1991). However, the significance of the greater number of female figurines in the corpus at Harappa and at other Indus sites, often interpreted as religious (e.g., Kenoyer 1998:134), is unclear.

Some scholars have interpreted the higher frequency of female representation in some ancient societies as evidence of religious significance or even female domination in ancient societies (e.g., Gimbutas 1982). In fact, there are no historical or archaeological examples to date of matriarchal societies in which women systematically and exclusively dominated men (Brettel and Sargent 1993:39; Eller 2000; Townsend 1990:183). Other scholars have suggested that the predominance of female representation typical of the Neolithic period may represent material objectification indicating the subordination of females (e.g., Hodder 1991) or (less convincingly) the manufacture and use of figurines by women (e.g., Lesure 2002) or a preference for female offspring (Hamilton 1996:285, citing Ucko 1968). None of these interpretations seems to be supported by mortuary evidence at Harappa, since the richness of grave goods of males and females is not significantly different (Dales et al. 1991), although the types of objects buried with males and females do sometimes differ. Of course, mortuary evidence may not always reflect the status or authority of persons in life (e.g., Townsend 1990: 188).

The explicit and somewhat exaggerated depiction of nipples on the male figurines, a subtle physiological feature without reproductive importance, may provide some insight into conceptions of sex, gender, and sexuality in Indus society, especially given the relative crudeness of most of the terracotta figurines and the generally minimalist approach to representing the features of the body (for example, fingers and even eyes) in this medium. The nipples may be imbued with cultural and symbolic significance, mirroring the breasts not in physiological prominence or reproductive importance, but as a symbolic repository of male sex, gender, and sexuality. Perhaps non-Western ideology provides a better analogy (but not necessarily a direct explanation). For example, in later Vedic belief, notions of the hydraulic system of the human body require balance between the similar (and dangerous) body fluids (blood, milk - produced by both males and females-, and semen), and the fluids of the upper body are considered positive, while the fluids of the lower body are considered negative (O'Flaherty 1980:55). In Tantric ritual, the control and retention of semen (through asceticism) is even believed to cause the yogi to turn his seed into milk and to develop "breasts" (O'Flaherty 1980:58).

The equivalence in the representation of male and female upper bodies and the mixed attributes on a few figurines probably indicate that the concepts of sex, gender, and sexuality in the Indus civilization were both complex and somewhat fluid. Analyses of other ancient societies (e.g., Joyce 2000; Meskell 1999) indicate that fluid conceptions of gender were not unusual and that other axes of difference such as life stage or age were sometimes equally or more important to 
depict. Rather than a reiteration of the analogy and implied connection with the sexual dualism found in Hinduism that has been used repeatedly since the earliest publications (e.g., Marshall 1931), sex and gender in the Indus civilization should be reconceptualized as unique, divorced completely from later religions such as Hinduism. Indus concepts of sex, gender, and sexuality probably did not conform to the discrete categories envisioned by the Western paradigm, but rather to graded categories with a "nuanced concept of sex" (Meskell 1999:76) interacting with other axes of difference. They may have varied across the vast geographical area under the cultural veneer of the Indus civilization as well. Perhaps this fluidity is another reflection of the ideology of this enigmatic civilization in which other signs of social differentiation and individual aggrandizement are few. The Harappans' implicit values and assumptions regarding sex and gender were surely encoded in the figurines through shape, the presence of sex attributes, dress, ornamentation, and certain postures. While the body is not a simple surface upon which a society inscribes its norms, representations of the body are representations of a society as much as physiology.

\section{ACKNOWLEDGMENTS}

This research was made possible through the generous cooperation of the Department of Archaeology of the Government of Pakistan, particularly the Harappa Museum and the National Museum of Pakistan; the Harappa Archaeological Research Project; the Lahore Museum; the Archaeological Survey of India; and the National Museum of India. The American School of Prehistoric Research and the Harappa Archaeological Research Project have provided financial support. This paper was much improved by the comments of Richard Meadow, C. C. Lamberg-Karlovsky, Rita Wright, Lynn Meskell, J. Mark Kenoyer, and Irene Good. Any errors, however, are solely my responsibility. I also owe a great debt to the late George Dales for his pioneering research with the figurines at Harappa and elsewhere, which I have aspired to carry on.

\section{NOTES}

1. Traditions of gender variance in modern South Asia are of particular interest as analogies for conceptions of sex and gender in the Indus civilization, just as modern terracotta figurine traditions provide analogies for Indus terracotta figurines. However, no connection between the hijras and the terracotta figurines is being implied here.

2. All B.C. dates are based on calibrated radiocarbon dates from Harappa.

3. Originally used by Wheeler (1947:128), "globular" is used here as a less loaded term than the terms "fat," "matronly," and "grotesque" used elsewhere.

4. Initial studies of people buried in the same cemetery at Harappa suggest that the women may have been related to each other by descent, while the men were not strongly related (Kenoyer 1998: 133, citing Hemphill et al. 1991).

\section{REFERENCES CITED}

AjoOtian, A.

1997 The only happy couple: Hermaphrodites and gender, in Naked Truths: Women, Sexuality, and Gender in Classical Art and Archaeology: 220-242, ed. A. O. Koloki-Ostrow and C. L. Lyons. London: Routledge.

AlcofF, L

1997 Cultural feminism versus post-structuralism: The identity crisis in feminist theory, in The Second Wave: A Reader in Feminist Theory: 330-355, ed. L. Nicholson. New York: Routledge. 
Appadurai, A.

1986 The Social Life of Things: Commodities in Cultural Perspective. Cambridge: Cambridge University Press.

Ardeleanu-Jansen, A.

1993 Die Terrakotten in Mohenjo-daro: Eine Untersuchung zur keramischen Kleinplastik in MohenjoDaro, Pakistan (ca. 2300-1900 v. Chr.). Aachen: Aachen University Mission.

2002 The terracotta figurines from Mohenjo Daro: Considerations on tradition, craft and ideology in the Harappan civilization (c. 2400-1800 B.c.), in Indian Archaeology in Retrospect, vol. 2, Protohistory: Archaeology of the Harappan Civilization: 205-222, ed. S. Settar and R. Korisettar. New Delhi: Manohar.

Atre, $\mathrm{S}$

1998 The high priestess: Gender signifiers and the feminine in the Harappan context. South Asian Studies 14:161-172.

2002 Harappan religion: Myth and polemics, in Indian Archacology in Retrospect, vol. 2, Protohistory: Archaeology of the Harappan Civilization: 185-204, ed. S. Settar and R. Korisettar. New Delhi: Manohar.

BAILEY, D.

1996 The interpretation of figurines: The emergence of illusion and new ways of seeing. Cambridge Archaeological Journal 6(2):291-295.

Bertelsen, R., A. Lillehammer, and J.-R. Naess, eds.

1987 Were They All Men? An Examination of Sex Roles in Prehistoric Society: Acts from a Workshop Held in Utstein Kloster, Rogaland, 2-4 November 1979. Stavanger: Arkeologisk Museum i Stavanger.

Boivin, N., AND D. Q. Fuller

2002 Looking for post-processual theory in South Asian archaeology, in Indian Archaeology in Retrospect, vol. 2, Protohistory: Archaeology of the Harappan Civilization: 192-215, ed. S. Settar and R. Korisettar. New Delhi: Manohar.

Brettel, C. B., and C. F. Sargent, eds.

1993 Gender in Cross-Cultural Perspective. Englewood Cliffs, NJ: Prentice-Hall.

Brumfiel, E. M.

1992 Distinguished lecture in archeology: Breaking and entering the ecosystem-gender, class, and faction steal the show. American Anthropologist 94:551-567.

1996 Figurines and the Aztec state: Testing the effectiveness of ideological domination, in Gender and Archaeology: 143-166, ed. R. P. Wright. Philadelphia: University of Pennsylvania Press.

Butler, J.

1990 Gender Trouble: Feminism and the Subversion of Identity. New York: Routledge.

1993 Bodies That Matter: On the Discursive Limits of "Sex." New York: Routledge.

Clark, S. R.

2001 In search of the "Mother Goddess": Cultic interpretation and the terracotta figurines from Harappa. Paper presented at the European Association of South Asian Archaeology Annual Meeting, Paris, France.

CONKEy, M. W., And J. M. Gero

1997 Programme to practice: Gender and feminism in archaeology. Annual Revieu of Anthropology 26:411-437.

Conkey, M. W., AND J. Spector

1984 Archaeology and the study of gender, in Advances in Archaeological Method and Theory, vol. 7:1-29, ed. Michael B. Schiffer. New York: Academic Press.

Cyphers Guillén, A.

1993 Women, rituals, and social dynamics at ancient Chalcatzingo. Latin American Antiquity $4(3): 209-224$.

DALES, G. F.

1960 Mesopotamian and Related Female Figurines: Their Chronology, Diffusion, and Cultural Functions. Unpublished Ph. D. diss., University of Pennsylvania, Philadelphia.

1984 Sex and stone at Mohenjo-daro, in Frontiers of the Indus Civilization: 109-115, ed. B. B. Lal and S. P. Gupta. New Delhi: Books and Books. 
1991 a The phenomenon of the Indus civilization, in Forgotten Cities on the Indus: Early Civilization in Pakistan from the 8th to the 2nd Millennium B.C.: 129-144, ed. M. Jansen, M. Mulloy, and G. Urban. Mainz: Verlag Philipp von Zabern.

$1991 \mathrm{~b}$ Some specialized ceramic studies at Harappa, in Harappa Excavations 1986-1990: 61-69, ed. Richard H. Meadow. Madison, WI: Prehistory Press.

Dales, G. F., J. M. Kenoyer, and the staff of the Harappa Project

1991 Summaries of five seasons of research at Harappa (District Sahiwal, Punjab, Pakistan), 1986-1990, in Harappa Excavations 1986-1990: 185-262, ed. R. H. Meadow. Madison, WI: Prehistory Press.

During Caspers, E.C.L.

1979 Caricatures, grotesques and glamour in Indus Valley art, in South Asian Archacology 1977: 345-374, ed. M. Taddei. Naples: Istituto Universitario Orientale.

ELIADE, M.

1964 Shamanism: Archaic Techniques of Ecstasy. Translated by Willard R. Trask. Revised and enlarged. Princeton: Princeton University Press.

ElLer, C.

2000 The Myth of Matriarchal Prehistory: Why an Invented Past Will Not Give Women a Future. Boston: Beacon Press.

Fausto-Sterling, A.

1993 The five sexes: Why male and female are not enough. The Sciences 33(2):20-25.

Flavin, K., I. Ali, and G. Erdosy

1995 The terracotta human figurines. Excavations in the Gomal Valley: Rehman Dheri report No. 2. Ancient Pakistan 10:82-133.

Gailey, C. W.

1987 Evolutionary perspectives on gender hierarchy, in Analyzing Gender: A Handbook of Social Science Research: 32-67, ed. B. B. Hess and M. Marx Ferree. Newbury Park: Sage.

Gatens, $M$.

1996 Imaginary Bodies: Ethics, Power, and Corporeality. New York: Routledge.

GiLCHRIST, R.

1999 Gender and Archaeology: Contesting the Past. New York: Routledge.

Gilchrist, R., ED.

2000 Human Lifecycles. World Archaeology 31(3). New York: Routledge.

Gimbutas, M. A.

1982 The Goddesses and Gods of Old Europe, 6500-3500 B.C.: Myths and Cult Images. 2nd ed. London: Thames and Hudson.

GoOdfellow, P. N.

2000 Sex and molecular biology, in Gender and Society: Essays on Herbert Spencer Lectures Given in the University of Oxford: 1-12, ed. C. Blakemore and S. Iversen. Oxford: Oxford University Press.

GORdon, D. H., AND M. E. GORdon

1940 Mohenjo-daro: Some observations on Indian prehistory. Iraq 7:1-12.

Grosz, E.

1994 Volatile Bodies: Toward a Corporeal Feminism. Bloomington: Indiana University Press.

1995 Space, Time, and Perversion: Essays on the Politics of Bodies. New York: Routledge.

Hamilton, N.

1996 The personal is political. Cambridge Archaeological Journal 6(2):282-285.

Hemphill, B. E., J. R. Lukacs, and K.A.R. Kennedy

1991 Biological adaptations and affinities of Bronze Age Harappans, in Harappa Excavations 1986-1990: 137-182, ed. R. H. Meadow. Madison, WI: Prehistory Press.

Herdt, G. H., ED.

1994 Third Sex, Third Gender: Beyond Sexual Dimorphism in Culture and History. New York: Zone Books. 
HODDER, I.

1991 Gender representation and social reality, in The Archaeology of Gender: 11-16, ed. D. Walde and N. D. Williams. Calgary: University of Calgary Archaeological Association.

JARRIGE, C.

1984 Terracotta human figurines from Nindowari, in South Asian Archaeology 1981: 129-134, ed. B. Allchin. Cambridge: Cambridge University Press.

1991 The terracotta figurines from Mehrgarh, in Forgotten Cities on the Indus: Early Civilization in Pakistan from the 8th to the 2nd Millennium B.C.: 87-93, ed. M. Jansen, M. Mulloy, and G. Urban. Mainz: Verlag Philipp von Zabern.

Joyce, R. A.

1996 The construction of gender in Classic Maya monuments, in Gender and Archaeology: 167195, ed. R. P. Wright. Philadelphia: University of Pennsylvania Press.

2000 Gender and Power in Prehispanic Mesoamerica. Austin: University of Texas Press.

KANG, K. S.

1988 Punjab Art and Culture. Delhi: Atma Ram and Sons.

KENNEDY, K.A.R.

2000 Conversation at Society for Harappan Studies meeting, Manchester, VT, 19 August.

KENOYER, J. M.

1998 Ancient Cities of the Indus Civilization. Karachi: Oxford University Press.

KENYON, K. M.

1969 Women in academic life. The Galton Lecture 1969. Journal of Biosocial Science, Supplement 2:107-118.

Knapp, A. B., and L. M. Meskell

1997 Bodies of evidence in prehistoric Cyprus. Cambridge Archaeological Journal 7(2):183-204.

LAQUEUR, T.

1990 Making Sex: Body and Gender from the Greeks to Freud. Cambridge: Harvard University Press.

LESURE, R.

1997 Figurines and social identities in early sedentary societies of coastal Chiapas, Mexico, in Women in Prehistory: North America and Mesoamerica: 227-248, ed. C. Claassen and R. Joyce. Philadelphia: University of Pennsylvania Press.

2002 The goddess diffracted: Thinking about the figurines of early villages. Current Anthropology $43(4): 587-610$.

MACKAY, E.J.H.

1938 Further Excavations at Mohenjo-Daro, vols. 1-2. New Delhi: Government of India.

Marcus, J.

1996 The importance of context in interpreting figurines. Cambridge Archaeological Journal $6(2): 285-291$

1998 Women's Ritual in Formative Oaxaca: Figurine-making, Divination, Death and the Ancestors. Memoirs of the Museum of Anthropology, University of Michigan, No. 33. Ann Arbor: University of Michigan.

Marshall, J. H., ed.

1931 Mohenjo-daro and the Indus Civilization, vols. 1-3. London: A. Probsthain.

MEADOW, R. H.

2002 Conversation, Cambridge, MA, 15 July.

MeAdow, R. H., ANd J. M. KenOyer

1997 Excavations at Harappa 1994-1995: New perspectives on the Indus script, craft activities, and city organization, in South Asian Archacology 1995: 139-172, ed. R. Allchin and B. Allchin. New Delhi: Oxford and IBH.

2000 The 'tiny steatite seals' (incised steatite tablets) of Harappa: Some observations on their context and dating, in South Asian Archaeology 1997: 321-340, ed. M. Taddei and G. de Marco. Rome: Istituto Italiano per l'Africa e l'Oriente.

Meadow, R. H., J. M. Kenoyer, and R. P. Wright

1997 Harappa Archaeological Research Project: 1997 excavations. Submitted to the Department of Archaeology and Museums, Government of Pakistan. 
2001 Harappa Archaeological Research Project: Harappa excavations 2000 and 2001. Submitted to the Department of Archaeology and Museums, Government of Pakistan.

Meskell, L. M.

1999 Archacologies of Social Life: Age, Sex, Class et cetera in Ancient Egypt. Oxford: Blackwell Publishers Ltd.

2001 Archaeologies of identity, in Archacological Theory Today: 187-213, ed. I. Hodder. Cambridge: Polity Press.

2002 Private Life in New Kingdom Egypt. Princeton: Princeton University Press.

MOORE, H. L.

1988 Feminism and Anthropology. Minneapolis: University of Minnesota Press.

NANDA, S.

1999 Neither Man Nor Woman: The Hijras of India. 2nd ed. Belmont: Wadsworth.

2000 Gender Diversity: Crosscultural Variations. Prospect Heights, II: Waveland Press.

Nordbladh, J., and T. Yates

1990 This perfect body, this virgin text: Between sex and gender in archaeology, in Archaeology after Structuralism: Post-Structuralism and the Practice of Archaeology: 222-237, ed. I. Bapty and T. Yates. New York: Routledge.

O'Flaherty, W. D.

1980 Women, Androgynes, and Other Mythical Beasts. Chicago: University of Chicago Press.

POLLOCK, S.

1991 Women in a men's world: Images of Sumerian women, in Engendering Archaeology: Women in Prehistory: 366-387, ed. J. M Gero and M. W. Conkey. Oxford: Blackwell.

Possehl, G. L.

1996 The Indus Age: The Writing System. Philadelphia: University of Pennsylvania Press.

1998 Sociocultural complexity without the state: The Indus civilization, in Archaic States: 261291, ed. G. M. Feinman and J. Marcus. Santa Fe: School of American Research Press.

2002 The Indus Civilization: A Contemporary Perspective. Walnut Creek: Alta Mira Press.

ROSCOE, W.

1996 Priests of the goddess: Gender transgression in ancient religion. History of Religions 35(3) : 195-230.

SCHMidt, R. A.

2000 Shamans and northern cosmology: The direct historical approach to Mesolithic sexuality, in Archaeologies of Sexuality: 220-235, ed. R. A. Schmidt and B. L. Voss. New York: Routledge.

Schmidt, R. A., ANd B. L. Voss, eds.

2000 Archaeologies of Sexuality. New York: Routledge.

SøRENSEN, M.L.S.

2000 Gender Archaeology. Cambridge: Polity Press.

Sullivan, H. P.

1964 A re-examination of the religion of the Indus civilization. History of Religion 4(1):15-25.

TOWNSEND, J. B.

1990 The goddess: Fact, fallacy and revitalisation movement, in Goddesses in Religions and Modern Debate: 179-203, ed. L. W. Hurtado. University of Manitoba Studies of Religion, vol. 1. Atlanta: Scholars Press.

Uско, P. J.

1968 Anthroponorphic Figurines of Predynastic Egypt and Neolithic Crete with Comparative Material from the Prehistoric Near East and Mainland Greece. Royal Anthropological Institute Occasional Paper No. 24. London: Andrew Szmidla.

VATS, M. S.

1940 Excavations at Harappa, I-II. New Delhi: Government of India.

Westenholz, J. G.

1998 Goddesses of the ancient Near East 3000-1000 B.C., in Ancient Goddesses: The Myths and the Evidence: 63-82, ed. L. Goodison and C. Morris. London: British Museum Press. 
WHEELER, R.E.M.

1947 Harappa 1946: The defenses and Cemetery R37. Ancient India 3:59-130.

1968 The Indus Civilization. Supplementary volume to the Cambridge Ancient History of India. 3rd ed. Cambridge: Cambridge University Press.

WRIGHT, R. P.

1991 Women's labor and pottery production in prehistory, in Engendering Archaeology: Women in Prehistory: 194-223, ed. J. M. Gero and M. W. Conkey. Oxford: Blackwell.

\begin{abstract}
Despite significant theoretical advances, there is still no universally accepted paradigm for the investigation of sex and gender and little critical research on the subject in South Asian archaeology. Without deciphered texts, artifacts such as figurines that provide body imagery are invaluable in understanding these conceptions in ancient societies. This paper is a critical examination of representations of the body in the Indus civilization, focusing on the anthropomorphic terracotta figurines from Harappa and using more flexible notions of sex, gender, and sexuality to explore Indus conceptions of sexual difference as it relates to other aspects of social difference and identity. The meaningful combinations of the attributes of the represented Indus body may reflect complex and fluid concepts of sex, gender, and sexuality in Indus society that differed from later traditions and varied beneath the cultural veneer of the Indus Civilization with its unique ideology. KEYwOrDs: archaeology, Indus civilization, Harappa, terracotta, figurines, sex, gender, sexuality, sexual difference, life cycle, social difference, body.
\end{abstract}

